\title{
Osteoradionecrosis of the Jaws: A Review of Conservative and Surgical Treatment Options
}

\author{
Kiki C. A. L. Cheriex, MD ${ }^{1}$ Tim H. J. Nijhuis, MD, $\mathrm{PhD}^{1} \quad$ Marc A. M. Mureau, MD, $\mathrm{PhD}^{1}$ \\ ${ }^{1}$ Department of Plastic and Reconstructive Surgery, Erasmus MC, \\ University Medical Center Rotterdam, Rotterdam, The Netherlands \\ Address for correspondence and reprint requests Marc A.M. Mureau, \\ MD, PhD, Department of Plastic and Reconstructive Surgery, Erasmus \\ MC, University Medical Center Rotterdam, PO Box 2040, 3000 CA \\ J Reconstr Microsurg 2013;29:69-76. \\ Rotterdam, The Netherlands (e-mail: m.mureau@erasmusmc.nl).
}
Abstract
Keywords
- osteoradionecrosis
- hyperbaric oxygen
- conservative treatment
- surgical treatment

Although surgery still is the most important treatment modality in the management of head and neck cancer, radiotherapy is increasingly being used. Consequently, the majority of head and neck cancer patients are at risk of developing osteoradionecrosis of the jaws, which is the most serious and important complication of radiotherapy. This review presents the etiology, pathophysiology, diagnosis, classification, and prevention of osteoradionecrosis. In addition, the body of evidence regarding conservative as well as surgical treatment of osteoradionecrosis is reviewed, and studies on complications, tumor recurrence and patient survival, dental rehabilitation, and functional and aesthetic outcome after surgical treatment for osteoradionecrosis are discussed.
Although surgery is still the most important treatment modality in the management of head and neck cancer, radiotherapy (XRT) is increasingly being used, either as (neo)adjuvant therapy or as primary treatment with or without concurrent chemotherapy. ${ }^{1,2}$ Despite significant improvements in reconstructive (micro)surgery over the last years, which have made more extensive tumor resections feasible, about two thirds of patients still require adjuvant XRT or concurrent chemoradiotherapy to improve oncologic outcome. $^{2}$ Consequently, the majority of patients with head and neck cancer are at risk of developing osteoradionecrosis (ORN) of the jaws as a complication of XRT.

ORN is the most serious and important complication of XRT. It was defined by Marx in 1983 as the presence of exposed bone in an irradiated field that fails to heal within a 3-month period. ${ }^{3}$ The reported incidence of ORN in literature ranges from 0.9 to $35 \%$. However, a recent large retrospective review of 830 patients with head and neck cancer who received XRT in a 30-year time period showed an $8.2 \%$ incidence of ORN of the jaws. ${ }^{4}$

\section{Etiology, Pathophysiology, and Prevention of ORN}

\section{Etiology}

ORN is one of the late complications after XRT. The most common location for ORN is the mandible, most likely because of its relatively poor vascularization. ${ }^{2,4}$ Early-stage ORN, within 2 years of XRT, is thought to be a result of a high radiation dose (>70 Gy) and/or associated surgical and/or radiation trauma. Late-stage ORN, several years after XRT, is often secondary to trauma within the devitalized tissues such as intraoral surgery. ${ }^{2,4}$

\section{Pathophysiology}

The pathophysiology of ORN seems to be a damaged microvasculature as a result of radiation induced endarteritis, thrombosis, and obliteration of vessels. In addition, the production of free radicals as a detrimental consequence of XRT impairs the ability of the bone to repair and remodel. Secondary lesions of these hypoxic tissues may then lead to infection of the previously weakened bone and soft tissues and to the development of a chronic, nonhealing wound. ${ }^{4}$ These effects of XRT were described by Marx as the " $3 \mathrm{H}$ 's": hypocellularity, hypoxia, and hypovascularity. ${ }^{2,3,5}$

More recently, another theory has been proposed stating that suppression of osteoclast-related bone turnover is the initial damage of the destructive ORN process. The underlying concept explains that osteoclasts sustain radiation damage prior to the development of vascular changes. It seems that "bisphosphonate-induced osteonecrosis" of the mandible supports this concept, as bisphosphonates also inhibit received

June 19, 2012

accepted

August 25, 2012

published online

December 19, 2012
Copyright (c) 2013 by Thieme Medical Publishers, Inc., 333 Seventh Avenue, New York, NY 10001, USA. Tel: +1(212) 584-4662.
DOI http://dx.doi.org/ 10.1055/s-0032-1329923. ISSN 0743-684X. 
osteoclast-mediated bone resorption and can result in osteonecrosis. $^{6}$

A wide range of risk factors that contribute to the development of ORN have been described. ${ }^{2,4-7}$ They can generally be divided into tumor-, patient-, or XRT-related risk factors. Tumor-related risk factors include tumor stage and size, the anatomical location, and the degree of involvement of neighboring bone structures. Patient-related risk factors include poor oral hygiene, periodontitis, extensive caries, and dentoalveolar surgery during XRT or in the early postoperative period. Alcohol consumption and smoking may also contribute to the development of ORN. XRT-related risk factors are the total dose delivered (increased risk $>60 \mathrm{~Gy}$, varying in the literature), dose fractionation (increased risk with fraction sizes $>2 \mathrm{~Gy}$ ), the size of the irradiated area, and the type of XRT used (brachytherapy or external beam irradiation).

\section{Prevention}

Prevention of ORN is of pivotal importance; hence, the risk factors mentioned earlier should be addressed whenever possible. Establishment of effective oral hygiene is very important, and every patient should have a full dental evaluation prior to XRT, including prophylactic oral care before, during, and after completion of XRT. ${ }^{2,5,6}$ All diseased teeth have to be extracted, optimally 2 to 3 weeks before starting XRT. All patients should be educated on meticulous oral hygiene and instructed to rinse with a fluoride and antibacterial mouthwash on a regular basis. All patients should have close follow-up by their dentist to ensure compliance.

Advances in the delivery of XRT are promising in reducing the incidence of ORN. Intensity-modulated radiotherapy (IMRT) and three-dimensional (3D) conformational XRT are two of these promising XRT protocols. Multiple studies have shown reduced incidence rates of around $6 \%$ with the use of these newer XRT techniques. ${ }^{6,8-10}$ One study even reported the absence of ORN in 176 patients treated with IMRT and a median follow-up of 34 months. ${ }^{11}$ According to the investigators this could not only be attributed to the use of IMRT, but also to meticulous oral hygiene and salivary gland sparing.

\section{Diagnosis and Classification of ORN}

Diagnosis of ORN is primarily based on clinical findings and patient history. ${ }^{5,12}$ ORN can manifest itself months to even years after irradiation of the area and usually starts with a nonhealing ulcer, eventually leading to exposure of necrotic bone. Secondary infection of the hypoxic tissues can cause severe pain with chewing or swallowing difficulties. In more progressed stages of ORN, bone sequestration can occur as well as trismus, orocutaneous fistula formation, local or systemic infection, and pathological fractures. Although the mucosal lesions may appear small, imaging techniques usually show more extensive underlying damage. Hence the combination of both computed tomography (CT) and magnetic resonance imaging (MRI) scanning can allow early diagnosis of ORN and can assist in visualizing the extent of ORN.

\section{Staging}

A few clinical staging systems for ORN have been proposed by different authors, but only that of Marx has been widely used. ${ }^{13}$ It is based upon response to therapy and consists of three stages. ${ }^{2}$ Problems with this staging system are that it is related to the use and response to hyperbaric oxygen (HBO) therapy, rather than to the pathophysiology of ORN itself, and that the disease cannot be staged before the treatment plan has been established and initiated.

Epstein et al tried to improve the classification of ORN in 1987 by describing the activity of the disease. ${ }^{12}$ Stage I is defined as healed, resolved ORN. Stage II includes patients with chronic ( $>3$ months), persistent but stable ORN. In stage III, patients have symptoms of progressive, active ORN. All three stages are subdivided in (a) "absence of pathologic fractures" and (b) "presence of pathologic fractures."

In 2002, Kagan and Schwartz again tried to improve the classification of ORN. ${ }^{14}$ In their three-stage system the disease is classified based on clinical and radiologic findings, and treatment is based on the stage. Stage I includes minimal soft-tissue ulceration and limited exposed cortical bone. These patients are treated conservatively. Stage II includes localized involvement of the mandibular cortex and underlying medullary bone. The majority of patients in this stage are also treated conservatively or are treated with minor surgical procedures. Stage III includes full thickness involvement of the bone, including the inferior border. Pathological fractures may be present. All patients in this stage require surgical treatment, including bone and/or soft-tissue replacement. Stage II and III are subdivided into (a) and (b), where (a) stands for minimal soft-tissue ulceration and (b) represents the presence of an orocutaneous fistula and mild soft-tissue necrosis.

\section{Treatment-Conservative Management}

In the early stages of ORN, when there is just a single small lesion, conservative management can be considered. Usually this consists of pain relief and treatment of infection with antibiotics. Small wounds may also be debrided superficially and loose necrotic bone may be removed. Over half of these early-stage lesions can be cured in this manner. ${ }^{2,5}$

Recently, new treatment possibilities have been proposed, such as the antioxidant agent pentoxifylline (PTX), a derivative of methylxanthine. It produces an anti-tumor necrosis factor- $\alpha$ effect, facilitates microcirculation, and inhibits inflammatory mechanisms, fibroblast proliferation, and the formation of extracellular matrix. ${ }^{5}$ It is used in the treatment of intermittent claudication and has been used in radiationinduced soft-tissue damage with some success, but its efficacy in ORN is still controversial. ${ }^{2}$ In addition, a synergic effect has been observed between PTX and tocopherol (vitamin E) in the treatment of ORN. Delenian et al administered to 54 patients prolonged treatment for ORN that involved a PTX dose of 800 $\mathrm{mg} /$ day and tocopherol $1000 \mathrm{IU} /$ day (5 days a week) and observed an $89 \%$ reduction in bone exposure after 12 months. $^{15}$

HBO therapy is another nonsurgical treatment modality for ORN. However, because there is still a shortage of 
conclusive evidence, the controversy of this treatment still remains and the discussion is ongoing. The use of HBO therapy is based on Marx's theory that ORN is a result of the " 3 H's." HBO is thought to increase the blood-tissue oxygen gradient, improving the diffusion of oxygen in hypoxic tissues, which in turn stimulates repair processes such as osteogenesis. It also improves angiogenesis by increasing the expression of growth factors such as vascular endothelial growth factor (VEGF). 5,6

HBO therapy can either be used therapeutically, in early stages of ORN, prophylactically to prevent ORN from developing, or in addition to surgical treatment. In accordance with Marx's original protocol, therapeutic use of HBO therapy is advised to consist of $30 \mathrm{HBO}$ dives to 2.4 atmospheres for 90 minutes. Good responders should continue to a total of 40 dives. Patients planned for more radical surgery, or patients facing preventative measures such as dental extractions, are advised to have 20 dives preoperatively followed by 10 dives postoperatively. ${ }^{16}$ Although HBO therapy seemed to be very effective in Marx's original studies, more recent studies showed less positive effects. ${ }^{17-21}$ Annane et al found in a prospective randomized controlled study during an interim analysis that patients treated with $\mathrm{HBO}(n=31)$ even fared worse compared with patients in the placebo $\operatorname{arm}(n=37) .{ }^{17}$ Therefore, the study was terminated beforehand. In a recent review on the efficacy of HBO therapy for ORN the authors concluded that according to new understandings of the physiopathology of ORN and according to the best evidence from high-quality randomized controlled trials, HBO therapy should not be recommended in the routine management of patients with mandibular ORN, except when resection and reconstruction surgery is needed. ${ }^{22}$

\section{Treatment-Nonmicrosurgical Management}

In the more advanced stages of ORN and in cases where conservative measures failed, surgical treatment is required. First, a possible local recurrence of a malignancy should be excluded via a biopsy. ${ }^{2}$ The study by Hao et al showed that in $21 \%$ of their studied population ( $n=33$ ) the diagnosis of ORN was later changed in recurrent cancer after taking a biopsy. ${ }^{23}$ Therefore, some experts think that surgical treatment for ORN should be as radical as primary tumor surgery. Furthermore, a CT-scan or MRI should be made preoperatively to assess the margins of resection. Still, the definite extent of resection can only be determined intraoperatively with margins that show healthy, bleeding bone. ${ }^{21,24}$

As Marx described in his stage III ORN, the more advanced stages could be managed by performing a sequestrectomy in combination with bony stabilization with a reconstruction plate after an initial HBO treatment of 30 dives. Immediate soft-tissue coverage is obtained by using a pedicled myocutaneous flap, as primary closure is usually impossible. Usually a regional pedicled flap, such as the pectoralis major myocutaneous flap, is used, but the latissimus dorsi, trapezius, or sternocleidomastoid flap may also be used in particular cases. ${ }^{2}$ About 3 months later bony reconstruction is performed using a nonvascularized bone graft. Some current literature advocates that the patient should receive $10 \mathrm{HBO}$ sessions after initial sequestrectomy, before planning the bony reconstruction and flap coverage approximately 10 to 12 weeks later. ${ }^{2,25}$

\section{Treatment-Microsurgical Reconstruction}

Most experts feel that the availability of reconstructive microvascular surgery has made Marx's algorithm of preoperative HBO followed by resection and delayed nonvascularized bone graft reconstruction outdated and of questionable efficacy. ${ }^{2}$ It has been generally accepted that wide, radical resection of necrotic bone with immediate free flap reconstruction is often the only and best option for the treatment of advanced ORN. ${ }^{2}$

\section{Reconstruction Goals}

Bony reconstruction of the mandible has presented multiple problems in the past with low success rates and high morbidity. ${ }^{26}$ The mandible contributes to airway stability and is important in mastication, deglutition and speech. In addition, it largely determines the shape of the lower face. Consequently, these functional and aesthetic qualities of the mandible are the specific goals in mandible reconstruction and are all equally important. ${ }^{24}$ Important functional goals include preservation of tandem temporomandibular joint action with maximal opening ability and maintenance of occlusion. Symmetry, preservation of lower facial height and anterior chin projection, and correction of submandibular soft-tissue neck defects are the main aesthetic goals.

\section{Free Flap Choice}

A few criteria are essential in the preoperative planning for microsurgical reconstruction after ORN. The first criterion is the necessity for sufficient amount of bone stock for reconstruction of the mandible or maxilla. Second, the soft-tissue paddle of the selected free flap should also be sufficient, as often there is considerable soft-tissue loss as well. Finally, the vessels of the flap should be of sufficient diameter and length, because often there are no suitable recipient vessels in the neck due to previous surgery and XRT. Usually, recipient vessels outside the radiated area have to be selected, such as the transverse cervical or thoracoacromial vessels. ${ }^{27-29}$

\section{Osteofasciocutaneous Free Flaps}

\section{Radial Forearm Flap}

The radial forearm flap has a relatively constant and reproducible vascular anatomy with long and large vessels. It can also be raised as an osteofasciocutaneous flap incorporating a segment of the distal radius, although the height and bone stock are limited. This makes the flap suitable for selected maxillary defects. ${ }^{30}$ Other advantages are the presence of both a superficial and deep venous system and the versatility in flap design. ${ }^{31-33}$

Disadvantages are the risk of a fracture when harvesting bone (for which prophylactic plating is suggested) and the need for sacrificing a major artery in the arm, which can compromise the vascular supply of the hand. ${ }^{30,31}$ 


\section{Scapula Flap}

The scapula flap is a reliable flap with a consistent vascular pedicle of sufficient length and caliber. Because it is possible to harvest this flap as a true chimera flap including multiple tissues (skin, fat, muscle, and bone) supplied by one vascular pedicle, its popularity for reconstruction of ORN defects is increasing. Another advantage is the minimal functional shoulder morbidity after harvesting this flap. ${ }^{34}$ In addition, skin color match with the head and neck area is better compared with other more distant flaps, and in most individuals it includes non-hairbearing skin. ${ }^{34}$

Disadvantages include the possible need for additional skin grafting to close the donor area and the position of the patients (prone or lateral decubitus), which could jeopardize a convenient reconstruction of the mandible and soft tissues. ${ }^{34}$

\section{Fibula Flap}

Compared with other flaps, the fibula flap is superior regarding bone length and vascularization. A long single bone segment up to $26 \mathrm{~cm}$ in adults can be harvested, but for most bony head and neck defects multiple osteotomies are preferable to allow contouring. The resulting short fibula segments are vascularized by segmental circular arterial branches originating from the peroneal artery. Therefore, it has become one of the most commonly used vascularized osteofascio(myo)cutaneous flaps. The fibula flap may also contain muscle (flexor hallucis longus and/or soleus), overlying fascia and, if necessary, skin. In contrast to the iliac crest flap, the skin paddle can be designed and inset in a more versatile manner and can therefore create an aesthetic and functional more rewarding result.

Usually, patients have very little donor-site problems; however, possible complications are limited ankle function and discomfort, flexor hallucis longus contractures, skin graft failure, and displeasing donor site scarring. ${ }^{35-37}$

\section{Iliac Flap}

One of the most common applications of the iliac flap is mandibular reconstruction, because of its generous amount of cortical and cancellous bone and curved shape. ${ }^{25}$ The flap can provide a bone segment with a total length of $16 \mathrm{~cm}$. It is essential to create a mandible-like shape, and a minimum height of $2 \mathrm{~cm}$ is advised for optimal mandibular reconstruction. The flap is supplied by the deep circumflex iliac vessels. Aside from the bone, a skin and/or muscle paddle can be included for soft tissue reconstruction.

Flap dissection can be lengthy and tedious, and the flap has a rather thick and immobile muscle and/or skin paddle that may be too bulky for intraoral soft-tissue reconstruction. In addition, serious donor-site problems such as abdominal contour deformity, herniation, lack of sensibility, painful neuropathy, gait disturbance, and the need for mesh reinforcement after harvest of a bicortical bone flap have been reported to occur in 10 to $25 \%{ }^{25}$

\section{Soft-tissue only Free Flaps}

To provide bone continuity, a bone flap is the most favorable flap for mandible reconstructions. However, this is not always necessary, as bone reconstruction is particularly important in anterior mandible defects. ORN often involves the lateral or posterior body of the mandible, in which bone reconstruction is less essential. ${ }^{38,39}$ Kroll et al evaluated 854 free flaps for oncologic reconstruction and concluded that bone flaps were nearly five times more likely to fail than soft-tissue only flaps. ${ }^{40}$ Therefore, using a soft-tissue only flap to fill the mandible defect, such as an ALT flap or a rectus abdominis flap, can lead to a satisfactory outcome. Functional and aesthetic outcome of soft-tissue versus bone flaps has not yet been studied well; however, Baumann et al showed no significant difference in their study evaluating outcome of free flap reconstruction in ORN patients $(n=63){ }^{38}$

\section{Rectus Abdominis Free Flap}

The rectus abdominis is a reliable flap with low morbidity and low complication rates. ${ }^{41}$ Its main advantages are the relatively easiness to harvest, the large caliber vessels, and the relatively large pedicle. ${ }^{40,41}$ Kroll et al reported that rectus abdominis flaps had a significantly lower failure rate $(0.9 \%)$ than all other flaps used (6.6\%), and also that the vascular thrombosis rate (2.5\%) was significantly lower compared with other flaps (7.8\%). ${ }^{40}$ However, after using this soft-tissue only flap, a loss of definition at the angle of the jaw and no functional temporomandibular joint (TMJ) at the side of the defect will occur. Dental implants are no option without having mandible reconstruction, and dental occlusion will be imperfect. ${ }^{39}$

\section{Anterolateral Thigh Flap}

Advantages of the ALT flap are multiple. It has a large vessel size and long vascular pedicle to facilitate anastomosis, and because the lateral femoral cutaneous nerve is included in the flap, it can potentially be a sensate flap. The vastus lateralis muscle can be included in this flap to gain more soft-tissue volume, and the thickness of this flap can be adjusted and thinned as well. ${ }^{42}$ It has a large cutaneous area, and the donor site can usually be closed primarily if the width is less than 6 to $8 \mathrm{~cm}$. Donor-site morbidity usually is minimal. ${ }^{43}$ Moreover, while harvesting this flap, there is no need for positional changes and it can be harvested simultaneously using a twoteam approach.

\section{Double Free Flaps}

According to Urken et al, soft-tissue reconstruction has an equal or even greater effect on functional outcome than bony reconstruction, and soft-tissue volume deficiency is poorly tolerated in the head and neck area. ${ }^{44}$ Fluids may accumulate in nonobliterated dead spaces that may lead to secondary infections, threatening flap survival. Dead spaces often contract, leading to a sunken appearance causing difficulties in speech, swallowing, and chewing. For watertight intraoral closure, sufficient soft tissue should be available to prevent salivary contamination, which can also jeopardize flap survival. ${ }^{45,46}$ Because the soft tissues attached to an osseous free flap are not always large and mobile enough to reconstruct a composite through-and-through defect of the mandible, a second free flap is sometimes necessary for adequate reconstruction. It allows easier insetting and better reproduction of 
the 3D anatomic boundaries. Still, according to a study by Wei et al, double free flaps were only indicated for mandibular reconstruction in 18\% (36 of 201 composite mandibular defects) in which ablative surgery was performed for advanced buccal carcinoma. ${ }^{46}$ Andrades et al performed double free flap reconstructions of the mandible in only $5 \%$ in more than 1000 free flap head and neck reconstructions. ${ }^{47}$ Indications for double free flaps were (1) extensive skin resection or presence of radiodermatitis in the neck that had to be excised; (2) extensive mucosal resection/removal of soft palate, lateral pharyngeal wall, part of the tongue and floor of the mouth, pterygoid fossa dissection, and inferior maxillectomy leaving the maxillary sinus open; (3) large mandibular bone defects with substantial loss of the overlying and underlying soft tissues; and (4) anticipation of difficult insetting with a single free flap because of the extent and tridimensional nature of the defect. ${ }^{46}$

Other authors agreed that double free flaps have proven to be useful, but only in extensive mandibular defects, as the procedure is surgically challenging and the patients' condition is usually poor. Therefore, local complication rates are often higher, and aesthetic and functional outcomes (speech, swallowing) are usually modest. ${ }^{45,47-49}$ There is also the need for two sets of recipient vessels in the neck, which can be extremely challenging to find in previously irradiated patients. The second flap can also be connected to the distal offspring of the first flap; however, this is not preferable, as occlusion in one flap can lead to the loss of both flaps. ${ }^{49}$

The fibula osteoseptocutaneous flap is mostly used in combination with a second soft-tissue free flap-such as the radial forearm, the ALT, or the rectus abdominis flap-to restore the massive soft-tissue loss. In 1999 Wei et al preferred using the fibula osteoseptocutaneous-radial forearm flap combination (20/36) in their series of 36 double free flap mandible reconstructions, followed by the fibula osteoseptocutaneous-rectus abdominis myocutaneous free flap combination (11/36). Later, with the increasing popularity of the ALT flap, a shift was made to the fibula osteoseptocutaneousALT flap combination (64/130), followed by the fibula osteoseptocutaneous-radial forearm flap (20/130), and the fibula osteoseptocutaneous-rectus abdominis flap (15/130). ${ }^{46,50}$ Nowadays, more authors seem to prefer the use of the fibula osteoseptocutaneous-ALT flap combination ${ }^{48,49,51}$ however, the radial forearm flap is still a popular alternative. ${ }^{47}$

\section{Recipient Vessel Selection}

Using free flaps is challenging in patients who had previous surgery and/or XRT due to the depleted amount of blood vessels, resulting in longer operating times and the need for additional incisions or harvesting of vein grafts. ${ }^{27,29,50} \mathrm{Nev}-$ ertheless, usually microsurgical reconstruction is still feasible in these "frozen" necks. ${ }^{27,28}$ Often the standard recipient vessels as the facial, lingual, and superior thyroid vessels are not available anymore. Therefore, the external carotid, transverse cervical, thoracoacromial, or internal mammary arteries usually have to be selected. The internal or external jugular, transverse cervical, cephalic, or internal mammary veins are mostly used for venous drainage in these reconstructions. ${ }^{27,28,52}$ Use of vein grafts is sometimes inevitable but leads to increased microsurgical complication rates. ${ }^{53-55}$

\section{Optimizing Outcome}

\section{Complications}

Surgical management of patients with ORN is complex and challenging, because of irradiation and previous surgery, which respectively cause wound healing problems and obliteration of tissue planes. ORN patients also have a higher risk of developing carotid artery atherosclerotic lesions, and in patients with previous free flap reconstruction, the choice of recipient vessels may be limited. ${ }^{24}$ Major postoperative complications that require surgical intervention occur from 0 to $32 \%{ }^{17,24,56}$ In 0 to $14 \%$, these major complications lead to partial or total free flap loss, which requires a second free flap or regional myocutaneous flap., $77,24,56,57$ In double free flaps, major complications rates of 30 to $50 \%$ are reported, with the same rate of flap survival compared with single free flap reconstructions (93 to 100\%). ${ }^{49}$ Minor complications, such as donor-site wound healing problems, infection, and orocutaneous fistula formation, occur in $8 \%$ to $30 \%$ of cases in the current literature. $7,17,24,57,58$

Baumann et al divided ORN defects in two groups: patients with simple mucosal defects and patients with complex through-and-through defects. ${ }^{38}$ In their series, patients with complex defects had a complication rate of 39\% (15 of 38 ), whereas patients with simple defects had a complication rate of $20 \%$ (5 of 25), although this difference was not statistically significant $(p=0.17)$. Within these groups, bone reconstructions were compared with soft-tissue only reconstructions. In patients with complex defects, the complication rates were significantly higher $(p=0.02)$ after the use of bone flaps (54\%; 13 of 24) than after soft-tissue only flaps (14\%; 2 of 14). However, in patients with simple defects these differences did not reach statistical significance ( $p=0.29)$, most likely due to the small sample size.

\section{Tumor Recurrence and Patient Survival}

Tumor recurrence rates after ORN reconstructions range from $0 \%$ to $25 \%$ in literature, with a maximum follow-up time of 62 months. Patient survival rates, not necessarily disease free, are usually around 70 to $80 \%$ with the same maximum followup time. $24,56-58$

\section{Functional and Aesthetic Outcome}

Studies on functional and aesthetic outcome after ORN are scarce. Baumann et al reported functional outcome of free flap reconstructions following ORN in 63 patients. ${ }^{38}$ In their series, $57 \%$ of patients could tolerate an oral diet, $26 \%$ required tube-feeding supplementation, and $16 \%$ were tube-feeding dependent at the time of their last follow-up. Mean follow-up was 18.2 months (range 3 to 72 months). The incidence of tube-feeding dependence was similar after bone and softtissue only flap reconstruction. In patients with complex through-and-through defects, a higher incidence of tubefeeding dependency was seen $(24 \%)$ than in patients with 
simple defects (4\%), although the difference was not statistically significant $(p=0.073)$.

Cordeiro et al reported long-term functional and aesthetic results of 133 fibula free flap reconstructions, of which only 8 were ORN cases. ${ }^{30}$ In this series, return to an unrestricted diet was seen in $45 \%$ of patients, $45 \%$ were able to eat a soft diet, and $5 \%$ were on a liquid diet. The other $5 \%$ required tube feeding. Speech was normal to near normal in $63 \%$, intelligible in $28 \%$, and unintelligible in $9 \%$. Aesthetic outcome was good to excellent in $59 \%$ of patients, fair in $27 \%$, and poor in $14 \%$. In general, patients with lateral and hemimandibular defects had better speech and aesthetic outcome than did patients with central defects.

Double free flap reconstructions have a poorer long-term aesthetic and functional outcome. Posch et al objectively scored function at follow-up (mean 3 years and 1 month) and found problematic speech, impaired deglutition, and oral incontinence in five, two, and four out of six patients, respectively. ${ }^{49}$ Aesthetic results were subjectively scored as good by three patients, neutral by one patient, and poor by two patients. Objective evaluation of aesthetics showed mainly color mismatch of external flaps (4/6), flap contracture of external flaps (3/6), flap bulkiness (2/6), and sagging of the flap (1/6). Some patients had more than one of the above. These somewhat disappointing results are similar to those of Gabr et al, ${ }^{45}$ but Jeng et $\mathrm{al}^{48}$ and Wei et $\mathrm{al}^{46}$ reported somewhat better results.

\section{Dental Rehabilitation}

Few patients receive osteointegrated dental implants after ORN reconstruction. There is limited evidence in literature that implants placed in the reconstructed areas have success and survival rates comparable to those obtained in case of implants placed in native bone. ${ }^{59,60}$ In the series of Chiapasco et al, 16 out of 59 fibula free flap reconstructions received a total of 72 dental implants. ${ }^{59}$ With a mean follow-up of 50.2 months (range 24 to 96 months), their cumulative success and survival rates at the end of follow-up time were $98.6 \%$ and $93.1 \%$ respectively, which is comparable to success and survival rates of implants placed in native bone. In the series of Wu et al, 29 patients received a total of 117 dental implants after reconstruction for oral tumor surgery. ${ }^{60}$ In this study, the mean follow-up time was 47.8 months (range 24 to 84 months). The 1 -year and 5 -year cumulative survival rate of the dental implants was $96 \%$ and $91 \%$, respectively. The 1-year and 5 -year cumulative success rate of the implants was $95 \%$ and $87 \%$, respectively.

Failure of dental implants is mainly a result of infection, tumor recurrence and soft-tissue proliferation. ${ }^{60}$ The fibula free flap presents many advantages for implant placement, but its limited height sometimes makes implant-supported prosthetic rehabilitation difficult. A solution to that problem could be the double barrel fibula free flap, to allow simultaneous reconstruction of the maxilla and the mandible. ${ }^{60,61}$

\section{References}

1 Pang L, Jeannon JP, Simo R. Minimizing complications in salvage head and neck oncological surgery following radiotherapy and chemo-radiotherapy. Curr Opin Otolaryngol Head Neck Surg 2011;19:125-131
2 Rayatt S, Mureau MA, Hofer SO. Osteoradionecrosis of the mandible: etiology, prevention, diagnosis and treatment. Indian J Plastic Surg 2007;40:65-71

3 Marx RE. Osteoradionecrosis: a new concept of its pathophysiology. J Oral Maxillofac Surg 1983;41:283-288

4 Reuther T, Schuster T, Mende U, Kübler A. Osteoradionecrosis of the jaws as a side effect of radiotherapy of head and neck tumour patients-a report of a thirty year retrospective review. Int J Oral Maxillofac Surg 2003;32:289-295

5 Silvestre-Rangil J, Silvestre FJ. Clinico-therapeutic management of osteoradionecrosis: a literature review and update. Med Oral Patol Oral Cir Bucal 2011;16:e900-e904

6 Jacobson AS, Buchbinder D, Hu K, Urken ML. Paradigm shifts in the management of osteoradionecrosis of the mandible. Oral Oncol 2010;46:795-801

7 Celik N, Wei FC, Chen HC, et al. Osteoradionecrosis of the mandible after oromandibular cancer surgery. Plast Reconstr Surg 2002; 109:1875-1881

8 Eisbruch A, Harris J, Garden AS, et al. Multi-institutional trial of accelerated hypofractionated intensity-modulated radiation therapy for early-stage oropharyngeal cancer (RTOG 00-22). Int J Radiat Oncol Biol Phys 2010;76:1333-1338

9 Studer G, Grätz KW, Glanzmann C. Osteoradionecrosis of the mandibula in patients treated with different fractionations. Strahlenther Onkol 2004;180:233-240

10 Studer G, Studer SP, Zwahlen RA, et al. Osteoradionecrosis of the mandible: minimized risk profile following intensity-modulated radiation therapy (IMRT). Strahlenther Onkol 2006;182:283-288

11 Ben-David MA, Diamante M, Radawski JD, et al. Lack of osteoradionecrosis of the mandible after intensity-modulated radiotherapy for head and neck cancer: likely contributions of both dental care and improved dose distributions. Int J Radiat Oncol Biol Phys 2007;68:396-402

12 Epstein JB, Wong FL, Stevenson-Moore P. Osteoradionecrosis: clinical experience and a proposal for classification. J Oral Maxillofac Surg 1987;45:104-110

13 Marx RE. A new concept in the treatment of osteoradionecrosis. J Oral Maxillofac Surg 1983;41:351-357

14 Schwartz HC, Kagan AR. Osteoradionecrosis of the mandible: scientific basis for clinical staging. Am J Clin Oncol 2002;25: 168-171

15 Delanian S, Chatel C, Porcher R, Depondt J, Lefaix JL. Complete restoration of refractory mandibular osteoradionecrosis by prolonged treatment with a pentoxifylline-tocopherol-clodronate combination (PENTOCLO): a phase II trial. Int J Radiat Oncol Biol Phys 2011;80:832-839

16 Marx RE, Johnson RP, Kline SN. Prevention of osteoradionecrosis: a randomized prospective clinical trial of hyperbaric oxygen versus penicillin. J Am Dent Assoc 1985;111:49-54

17 Annane D, Depondt J, Aubert P, et al. Hyperbaric oxygen therapy for radionecrosis of the jaw: a randomized, placebo-controlled, double-blind trial from the ORN96 study group. J Clin Oncol 2004;22:4893-4900

18 Gal TJ, Yueh B, Futran ND. Influence of prior hyperbaric oxygen therapy in complications following microvascular reconstruction for advanced osteoradionecrosis. Arch Otolaryngol Head Neck Surg 2003;129:72-76

19 Maier A, Gaggl A, Klemen H, et al. Review of severe osteoradionecrosis treated by surgery alone or surgery with postoperative hyperbaric oxygenation. Br J Oral Maxillofac Surg 2000;38; 173-176

20 Mounsey RA, Brown DH, O’Dwyer TP, Gullane PJ, Koch GH. Role of hyperbaric oxygen therapy in the management of mandibular osteoradionecrosis. Laryngoscope 1993;103:605-608

21 Shaw RJ, Butterworth C. Hyperbaric oxygen in the management of late radiation injury to the head and neck. Part II: prevention. Br J Oral Maxillofac Surg 2011;49:9-13 
22 Bessereau J, Annane D. Treatment of osteoradionecrosis of the jaw: the case against the use of hyperbaric oxygen. J Oral Maxillofac Surg 2010;68:1907-1910

23 Hao SP, Chen HC, Wei FC, Chen CY, Yeh AR, Su JL. Systematic management of osteoradionecrosis in the head and neck. Laryngoscope 1999;109:1324-1327, discussion 1327-1328

24 Ang E, Black C, Irish J, et al. Reconstructive options in the treatment of osteoradionecrosis of the craniomaxillofacial skeleton. Br J Plast Surg 2003;56:92-99

25 Beahm EK, Hanasone MM, Shenaq S. Iliac flap. In: Wei FC, Mardini S, eds. Flaps and Reconstructive Surgery. Philadelphia: Saunders; 2009:339-408

26 Peleg M, Lopez EA. The treatment of osteoradionecrosis of the mandible: the case for hyperbaric oxygen and bone graft reconstruction. J Oral Maxillofac Surg 2006;64:956-960

27 Hanasono MM, Barnea Y, Skoracki RJ. Microvascular surgery in the previously operated and irradiated neck. Microsurgery 2009; 29:1-7

$28 \mathrm{Yu} \mathrm{P}$. The transverse cervical vessels as recipient vessels for previously treated head and neck cancer patients. Plast Reconstr Surg 2005;115:1253-1258

29 Krijgh DD, Mureau MA. Reconstructive options in patients with late complications after surgery and radiotherapy for head and neck cancer: remember the deltopectoral flap. Ann Plast Surg 2012. doi:10.1097/SAP.0b013e3182414612

30 Cordeiro PG, Disa JJ, Hidalgo DA, Hu QY. Reconstruction of the mandible with osseous free flaps: a 10-year experience with 150 consecutive patients. Plast Reconstr Surg 1999;104:1314-1320

31 Souter DS. Radial forearm flap. In: Wei FC, Mardini S, eds. Flaps and Reconstructive Surgery. Philadelphia: Saunders; 2009:321-338

32 Disa JJ, Cordeiro PG. Mandible reconstruction with microvascular surgery. Semin Surg Oncol 2000;19:226-234

33 Shaha AR, Cordeiro PG, Hidalgo DA, et al. Resection and immediate microvascular reconstruction in the management of osteoradionecrosis of the mandible. Head Neck 1997;19:406-411

34 Angrigiani C, Pefaure J, MackFarlane M. Scapular and parascapular flaps. In: Wei FC, Mardini S, eds. Flaps and Reconstructive Surgery. Philadelphia: Saunders; 2009:271-285

35 Winters HA, de Jongh GJ. Reliability of the proximal skin paddle of the osteocutaneous free fibula flap: a prospective clinical study. Plast Reconstr Surg 1999;103:846-849

$36 \mathrm{Yu}$ P, Chang EI, Hanasono MM. Design of a reliable skin paddle for the fibula osteocutaneous flap: perforator anatomy revisited. Plast Reconstr Surg 2011;128:440-446

37 Lin JY, Djohan R, Dobryansky M, et al. Assessment of donor-site morbidity using balance and gait tests after bilateral fibula osteoseptocutaneous free flap transfer. Ann Plast Surg 2009;62:246-251

38 Baumann DP, Yu P, Hanasono MM, Skoracki RJ. Free flap reconstruction of osteoradionecrosis of the mandible: a 10-year review and defect classification. Head Neck 2011;33:800-807

39 Kroll SS, Robb GL, Miller MJ, Reese GP, Evans GR. Reconstruction of posterior mandibular defects with soft tissue using the rectus abdominis free flap. Br J Plast Surg 1998;51:503-507

40 Kroll SS, Schusterman MA, Reece GP, et al. Choice of flap and incidence of free flap success. Plast Reconstr Surg 1996;98:459-463

41 Butler CE, Lewin JS. Reconstruction of large composite oromandibulomaxillary defects with free vertical rectus abdominis myocutaneous flaps. Plast Reconstr Surg 2004;113:499-507

42 Posch NA, Mureau MA, Flood SJ, Hofer SO. The combined free partial vastus lateralis with anterolateral thigh perforator flap reconstruction of extensive composite defects. Br J Plast Surg 2005;58:1095-1103

43 Mureau MA, Posch NA, Meeuwis CA, Hofer SO. Anterolateral thigh flap reconstruction of large external facial skin defects: a follow-up study on functional and aesthetic recipient- and donorsite outcome. Plast Reconstr Surg 2005;115:1077-1086

44 Urken ML, Weinberg H, Vickery C, Buchbinder D, Lawson W, Biller HF. Oromandibular reconstruction using microvascular composite free flaps. Report of 71 cases and a new classification scheme for bony, soft-tissue, and neurologic defects. Arch Otolaryngol Head Neck Surg 1991;117:733-744

45 Gabr E, Kobayashi MR, Salibian AH, et al. Mandibular reconstruction: are two flaps better than one? Ann Plast Surg 2004;52:31-35

46 Wei FC, Demirkan F, Chen HC, Chen IH. Double free flaps in reconstruction of extensive composite mandibular defects in head and neck cancer. Plast Reconstr Surg 1999;103:39-47

47 Andrades P, Bohannon IA, Baranano CF, Wax MK, Rosenthal E. Indications and outcomes of double free flaps in head and neck reconstruction. Microsurgery 2009;29:171-177

48 Jeng SF, Kuo YR, Wei FC, Su CY, Chien CY. Reconstruction of extensive composite mandibular defects with large lip involvement by using double free flaps and fascia lata grafts for oral sphincters. Plast Reconstr Surg 2005;115:1830-1836

49 Posch NA, Mureau MA, Dumans AG, Hofer SO. Functional and aesthetic outcome and survival after double free flap reconstruction in advanced head and neck cancer patients. Plast Reconstr Surg 2007;120:124-129

50 Yazar S, Wei FC, Chen HC, et al. Selection of recipient vessels in double free-flap reconstruction of composite head and neck defects. Plast Reconstr Surg 2005;115:1553-1561

51 Wei FC, Celik N, Chen HC, Cheng MH, Huang WC. Combined anterolateral thigh flap and vascularized fibula osteoseptocutaneous flap in reconstruction of extensive composite mandibular defects. Plast Reconstr Surg 2002;109:45-52

52 Jacobson AS, Eloy JA, Park E, Roman B, Genden EM. Vessel-depleted neck: techniques for achieving microvascular reconstruction. Head Neck 2008;30:201-207

53 van Driel AA, Mureau MA, Goldstein DP, et al. Aesthetic and oncologic outcome after microsurgical reconstruction of complex scalp and forehead defects after malignant tumor resection: an algorithm for treatment. Plast Reconstr Surg 2010;126:460-470

54 Miller MJ, Schusterman MA, Reece GP, Kroll SS. Interposition vein grafting in head and neck reconstructive microsurgery. J Reconstr Microsurg 1993;9:245-251, discussion 251-252

55 Bozikov K, Arnez ZM. Factors predicting free flap complications in head and neck reconstruction. J Plast Reconstr Aesthet Surg 2006;59:737-742

56 Chang DW, Oh HK, Robb GL, Miller MJ. Management of advanced mandibular osteoradionecrosis with free flap reconstruction. Head Neck 2001;23:830-835

57 Coskunfirat OK, Wei FC, Huang WC, Cheng MH, Yang WG, Chang YM. Microvascular free tissue transfer for treatment of osteoradionecrosis of the maxilla. Plast Reconstr Surg 2005;115:54-60

58 Alam DS, Nuara M, Christian J. Analysis of outcomes of vascularized flap reconstruction in patients with advanced mandibular osteoradionecrosis. Otolaryngol Head Neck Surg 2009;141:196-201

59 Chiapasco M, Biglioli F, Autelitano L, Romeo E, Brusati R. Clinical outcome of dental implants placed in fibula-free flaps used for the reconstruction of maxillo-mandibular defects following ablation for tumors or osteoradionecrosis. Clin Oral Implants Res 2006;17:220-228

60 Wu YQ, Huang W, Zhang ZY, Zhang ZY, Zhang CP, Sun J. Clinical outcome of dental implants placed in fibula-free flaps for orofacial reconstruction. Chin Med J (Engl) 2008;121:1861-1865

61 Chang YM, Wallace CG, Tsai CY, Shen YF, Hsu YM, Wei FC. Dental implant outcome after primary implantation into double-barreled fibula osteoseptocutaneous free flap-reconstructed mandible. Plast Reconstr Surg 2011;128:1220-1228 